\title{
Quality of Life and Memory after Vagus Nerve Stimulator Implantation for Epilepsy
}

\author{
Jeannette McGlone, Ivan Valdivia, Marsha Penner, Jaime Williams, \\ R. Mark Sadler, David B. Clarke
}

\begin{abstract}
Objective: This prospective, case control study evaluates quality of life (QOL), depressive affect, and memory outcomes of epilepsy patients implanted with a vagus nerve stimulator (VNS). Methods: Three groups of patients with epilepsy underwent assessment on two occasions: 1) patients with a VNS were tested before and 12 months after implantation $(\mathrm{n}=16)$; 2) patients who underwent cerebral resective surgery were tested pre- and post-operatively $(\mathrm{n}=10)$; and 3$)$ patients under medical management $(\mathrm{n}=9)$. Group means were compared on the QOLIE-89, Geriatric Depression Scale, Wechsler Memory Scale - III, and the Memory Observation Questionnaire. Secondary analyses calculated the reliable change index, providing information on change beyond measurement error and chance. Results: Mean ratings of QOL, depression, and memory complaints and objective memory scores remained stable or improved in all the groups. The QOL improved more after cerebral resective surgery than VNS or medication controls, but the VNS and medication control groups did not differ. In the VNS group, QOL was not related to seizure reduction. The percentage of cases showing real change in memory was equivalent across groups, except in one of eight indices (i.e., verbal recognition memory). Conclusions: This first case controlled design found that vagus nerve stimulation as an adjunctive therapy for seizure control did not change QOL, depressive affect, or objective memory scores over one-year more so than medical management alone. We point out the need for larger case control, non-industry funded investigations.
\end{abstract}

RÉSUMÉ: Qualité de vie et mémoire après implantation d'un stimulateur du nerf vague pour traiter l'épilepsie. Objectif : Le but de cette étude prospective cas-témoin était d'évaluer la qualité de vie $(\mathrm{QV})$, l'affect dépressif et la mémoire de patients épileptiques chez qui un stimulateur du nerf vague (SNV) a été implanté. Méthodes : Trois groupes de patients épileptiques ont été évalués à deux reprises : 1) des patients porteurs d'un SNV ont été évalués avant et 12 mois après son implantation $(\mathrm{n}=16)$; des patients qui ont subi une résection cérébrale chirurgicale ont été évalués avant et après la chirurgie $(\mathrm{n}=10) ; 3)$ des patients sous traitement médical $(\mathrm{n}=9)$. Nous avons comparé les moyennes des groupes pour les tests suivants : QOLIE89, Geriatric Depression Scale, Wechsler Memory Scale-III et Memory Observation Questionnaire. Nous avons également calculé le reliable change index, ce qui ajoute de l'information sur le changement qui n'est pas dû à l'erreur de mesure ou au hasard. Résultats : La moyenne des évaluations de la QV, de la dépression et des symptômes mnésiques et les scores objectifs d'évaluation de la mémoire sont demeurés stables ou se sont améliorés chez tous les groupes de patients. La QV s'est améliorée davantage après la résection cérébrale chirurgicale qu'après l'implantation d'un SNV ou chez les patients sous traitement médical. Cependant, aucune différence n'a été observée entre les groupes SNV et traitement médical. Dans le groupe SNV, la QV n'était pas reliée à la diminution des crises. Le pourcentage de cas qui présentaient un changement mnésique réel était équivalent dans tous les groupes sauf pour un des huit indices (la mémoire de reconnaissance verbale). Conclusions : Cette première étude cas-témoin a montré que la stimulation du nerf vague comme thérapie d'appoint pour le contrôle des crises n'a pas modifié la QV, l'affect dépressif ou les scores à l'évaluation de la mémoire objective un an après par rapport au traitement médical. Nous soulignons la nécessité d'études cas-témoin de plus grande envergure, non subventionnées par l'industrie.

Can. J. Neurol. Sci. 2008; 35: 287-296

Implantation of a vagus nerve stimulator (VNS) to decrease seizure frequency and severity became available for commercial application in Europe in 1994 and in the US since 1997. ${ }^{1}$ Randomized clinical trials have reported greater than $50 \%$ improvement in seizure control in 20 to 30 percent of patients experiencing therapeutic levels of stimulation..$^{2-4}$ Improved seizure control has been correlated with a longer follow-up
From the Department of Psychology (JMG, IV), Department of Pharmacology (MP), Department of Medicine (Neurology) (RMS), Department of Surgery (Neurosurgery) (DBC), Dalhousie University; Department of Psychology (JMG, JW), Queen Elizabeth II Health Sciences Centre, Halifax, NS; Department of Psychology (IV), The Ottawa Hospital, Ottawa, ON; Department of Psychology (JW), University of Saskatchewan, Saskatoon, SK, Canada.

Received November 6, 2007. Final Revisions Submitted February 9, 2008. Reprint requests to: Jeannette McGlone, Department of Psychology, Dalhousie University, Halifax, Nova Scotia, B3H 4J1, Canada. 
interval $^{5,6}$ and with earlier implantation in the course of the disease. ${ }^{7}$ However, only a small percentage of patients become seizure free. ${ }^{2,8}$ Chadwick $^{9}$ has concluded that, "the current evidence shows that VNS has an unequivocal although modest therapeutic effect against complex partial seizures."

\section{Vagus Nerve Stimulation and Quality of Life}

Although seizure control has historically been the focus of outcome research, current health care practices necessitate consideration of additional factors when determining successful treatment outcome. Subjective indices, such as quality of the patient's life, have come to the forefront in epilepsy research as central indicators of success. ${ }^{10,11}$ Several researchers have reported better quality of life (QOL) after VNS implantation, ${ }^{12-15}$ whereas others have not demonstrated such an effect. ${ }^{16,17}$ Although some researchers have concluded that QOL covaries with seizure reduction, it is important to note that those findings were restricted to small parts of the QOL questionnaire. ${ }^{18,19}$ For example, two blinded, large-scale VNS studies reported that patients who experienced $>50 \%$ reduction of seizure frequency (i.e., responders) showed more improvement on an item or a subscale of the QOL measure than did nonresponders. In the very same studies, the more reliable and valid QOL aggregate score (made up of many items and/or several subscales) did not differentiate between responders and nonresponders. ${ }^{13,20}$ Currently, an impression for positive QOL outcomes after VNS is emerging, despite methodological limitations of face validity scales, and the fact that most studies are industry funded. Documenting reliable and meaningful changes in quality of life associated with VNS constitutes an important step in the acceptance and widespread use of this device. ${ }^{21,22}$ One national guideline for selecting VNS as an adjunctive treatment specifically advises finding cases "...for whom a partial reduction in seizure frequency will significantly improve their quality of life". ${ }^{23}$ Consistent with this, continuing research on VNS outcomes should address measurement issues relevant to QOL questionnaires.

\section{Vagus Nerve Stimulation and Cognition}

The impact of VNS on memory function is also important to document. The first purely experimental study of VNS and memory claimed that low stimulation parameters (i.e., $0.5 \mathrm{~mA}$ ) administered immediately after learning word lists (i.e., during the consolidation phase) significantly enhanced retention on word-recognition memory. Under higher, clinically effective levels of stimulation (e.g., $0.75-1.5 \mathrm{~mA}$ ), memory was unchanged, and stimulation before learning trials had no effect whatsoever. ${ }^{24}$ Using similar methodology (i.e., VNS parameters of $0.5 \mathrm{~mA}$, verbal learning test) Ghacibeh and colleagues ${ }^{25}$ also found that VNS given after learning word lists improved retention of words over a 20-minute period, indicating a probable effect on consolidation. In an entirely different paradigm, high stimulation ( $>1 \mathrm{~mA}$ ) during both the presentation and recognition phases of the study resulted in selective decline of nonverbal memory, with no effect on verbal memory. ${ }^{26}$ These results are contradictory, and they do not address the concern of longer term outcomes in clinical samples.

Longitudinal studies of patients with epilepsy implanted with VNS found that scores on standardized neuropsychological tests of intelligence, attention, and psychomotor speed do not deteriorate over three- or six- month intervals. ${ }^{20,27}$ Similarly, case studies of reaction time, choice selection, and inhibition also showed no deterioration up to six months after VNS. ${ }^{28}$ In summary, there seems to be no adverse effect of VNS on cognition or psychomotor speed in the short term, but data on longer intervals and specifically on memory are needed.

Sackeim and colleagues ${ }^{29}$ investigated the effects of VNS on memory in a sample of patients who were implanted with the device for the treatment of depression. Such findings may inform future research on VNS in epilepsy patients, but appropriate caution must be warranted in terms of the generalization of findings to samples of patients with epilepsy. With such cautions in mind, Sackeim's team found that recall for verbal and nonverbal material showed no improvement over the ten-week interval. Higher scores postoperatively than pre-operatively on motor speed, speeded psychomotor functioning, and executive ability were also reported in this study. However, due to the possibility of a practice effect on second testing, it is unclear whether the higher scores indicate "no improvement" or "improvement. As pointed out by the authors, the use of a control group is necessary to determine whether VNS intervention produces more than a practice effect on memory functioning. ${ }^{29}$

\section{Rationale and Purpose}

Another limitation of previous VNS studies examining QOL or cognition is that the data analysis was confined to contrasts between group means. Thus far, no study has examined the magnitude of change necessary to conclude that gain or loss after VNS intervention is real or clinically meaningful on an individual level. ${ }^{22,30}$ The Reliable Change Index (RCI $)^{31}$ provides such a case by case analysis. The RCI sets an objective standard for interpreting the magnitude of change such that the range is outside of the limits of measurement error and/or chance.

Most studies examining the effect of VNS on quality of life or cognition utilize a repeated measures design, whereby VNS patients serve as their own control, ${ }^{12,13,17,19,27}$ or a between subjects design whereby VNS patients receiving higher, lower, or sham stimulation are compared to each other. ${ }^{20,24}$ To our knowledge, no VNS implantation study has used comparison groups of patients with epilepsy who were treated with different interventions. That medically managed cases seen in a tertiary care clinic report significantly improved QOL after one year has already been well documented, ${ }^{32}$ though not well understood. Hence it is imperative that VNS researchers use case control designs, before attributing increases in QOL to VNS stimulation intervention, per se. Accordingly, we compare VNS patients to two control groups: patients with epilepsy undergoing medical management and patients with epilepsy who have undergone cerebral resective surgery (RS). This case-matched prospective design allows us to determine the effects of VNS on cognition and quality of life, compared with other epilepsy treatments.

\section{Methods}

The study protocol received approval from the Queen Elizabeth II Health Sciences Centre (QEII HSC), Halifax, NS research ethics board prior to initiating recruitment, and patients provided informed consent. Provincial health plans funded the purchase of the device, as well as the medical and surgical care, on a case by case basis. 


\section{Study Participants}

Subjects older than 16 years and diagnosed with epilepsy by the epileptologist (R.M.S.) were included. There was no attempt to exclude patients on the basis of developmental delay, or comorbid psychiatric condition in any group. Sixteen consecutive cases given VNS implantation, representing the totality of our first two years of experience with this device constituted the cases (VNS). Patients offered VNS had medically uncontrollable complex partial seizures for five years or more, had no progressive neurological disorder as a cause of the epilepsy, and did not currently meet criteria for a surgical resection of the seizure focus. Seven VNS patients had not benefited from prior resection or callosotomy. Both patient and family were motivated to try the VNS intervention. Eleven patients whose epilepsy was treated with medications alone participated as controls (MC). They were selected from the larger database of active treatment cases attending an outpatient epilepsy clinic at the QEII HSC to match a VNS case within five years of age. Two MCs were lost to follow-up (i.e., one moved with no forwarding address, another refused to undergo re-test) and, therefore, were not tested twice. These two did not differ from the other nine in age, hand preference, self-reported education level (highest grade), or standard score on the WRATIII Reading achievement test. ${ }^{33}$

Ten cerebral resection patients were recruited who underwent either: an anterior temporal lobe resection $(n=8)$; selective amygdalohippocampectomy $(\mathrm{n}=1)$; or functional hemispherectomy $(n=1)$ during the same time period. Patients offered RS had been refractory to medical management for at least the two previous years (the laterality of the seizure focus was seven leftsided, three right-sided). All but one RS patient continued taking their medications over the year of follow-up.

\section{Medical and Surgical Procedures}

The stimulating electode and stimulator (NCP, Cyberonics Inc.) were implanted by the same neurosurgeon (DBC) in a manner described in McLachlan et al. ${ }^{15}$ The stimulator was activated at the time of implantation, and the current gradually increased over several weeks from $0.25 \mathrm{~mA}$ to $3.0 \mathrm{~mA}$, depending on the patient's response. Bi-polar stimulation with $0.5 \mathrm{msec}$ pulse-duration at $30 \mathrm{HZ}$ was used for 30 seconds every five minutes and the subsequent stimulation parameters were modified at the discretion of the epileptologist. Patients were supplied with a bar magnet for self initiated stimulation. Use of the latter is not reported here. Changes in medications and dosages occurred if clinically warranted over the study interval, with no attempt to control for this factor. A patient interview by the epileptologist determined the frequency of complex partial seizures for the month before entry into the study and for the month one year after entry/surgery.

\section{Psychological Measures}

\section{Quality of Life}

The Quality of Life Inventory in Epilepsy-89 (QOLIE-89) aggregate score measured self-reported quality of life. ${ }^{34}$ The aggregated score met published criteria of reliability, validity, and responsiveness to change. ${ }^{21,22}$ The four factors within the scale are intercorrelated and, therefore, the aggregate score is theoretically unified. Correlations between the aggregate QOLIE-89 and objective neuropsychological measures are low. ${ }^{21}$ T-scores (mean of 50, standard deviation, sd $=10$ ), rather than the raw scores are reported here because this statistic allows the reader added insight into the magnitude of change experienced by this sample in relation to variability present in the larger standardization sample of persons with epilepsy. Higher Tscores reflect more favourable QOL.

\section{Depressive Affect}

Depression is highly correlated with self-reported QOL, ${ }^{21}$ and the literature suggests there will be similar improvements in mood states between VNS and control groups. ${ }^{35}$ The Geriatric Depression $\mathrm{Scale}^{36}$ is a self-report questionnaire that assesses mood. It was chosen because the format is similar to that of the other questionnaires insofar as it consists of reading simple statements and indicating a "yes/no" response to each. It is also less influenced by the somatic/medical symptoms of depression. ${ }^{16,35,37}$ Hence the physical symptoms that are frequently part of seizures would not contribute to the depression score.

\section{Memory}

A subjective report of memory complaints, the Memory Observation Questionnaire $\left(\mathrm{MOQ}^{38}\right)$ and an objective memory battery, the Wechsler Memory Scale - III (WMS-III ${ }^{39}$ ) were used. The MOQ questionnaire consists of two forms: one completed by the patient and a parallel but shorter form completed by a significant other (i.e., relative or informant). Each form consists of two parts. Part A asks questions about current memory status pertinent to daily life. Part B elicits rating about change in memory functioning "over the past several months" (i.e., pre-operative) or, "since the operation" (i.e., postoperative). Therefore, the MOQ-SA and MOQ-SB refer to subject forms $\mathrm{A}$ and $\mathrm{B}$, respectively and the MOQ-RA and MOQ-RB refer to relative forms A and B respectively. The MOQ was standardized on a non-medical specific Canadian community sample. ${ }^{38}$ T-scores are reported with a mean of 50 and $\mathrm{sd}=10$. A high score reflects better memory ratings than does a low score. Prior research has shown the MOQ to be sensitive to change after temporal lobectomy, with patients reporting significantly fewer complaints and improved memory after their resection than before operation..$^{40,41}$

The WMS-III yielded eight major indices with a standardized mean of 100 (sd = 15). There are three memory indices: Immediate Memory, General Memory, and Working Memory; three auditory indices which assess verbal memory: Auditory Immediate Memory, Auditory Delayed Memory, and Recognition Memory; and two visual indices: Visual Immediate Memory, and Visual Delayed Memory.

Participants who scored below a grade 6 level on the Reading subscale of the Wide Range Achievement Test-III ${ }^{33}$ were excluded from analysis of the self-report questionnaires because illiteracy invalidates those results (e.g., 5 VNS, $1 \mathrm{MC}$, and $2 \mathrm{RS}$ ). Hence there are fewer data points in the self-report outcomes than the objective memory outcomes. 


\section{Statistical Analyses}

To test whether the VNS group improved in either objective or subjective psychological functioning, multiple Analyses of Variances were applied to the outcome measures. The between subject factor was Group (VNS, MC, RS) and the repeated, within subject factor was Time (first "Time 1" vs second "Time 2" testing). Post hoc Bonferroni t-tests were used to examine any significant main effect or interaction (i.e., reaching the $p$ $<.05)$. A second set of analyses were performed. The Reliable Change Index was calculated for each test based on the medication controls' data using the following formula: ${ }^{30}$

$$
\begin{array}{ll}
\underline{\mathrm{X}}_{1}-\mathrm{X}_{2}= & \underline{\mathrm{X}}_{1}-\mathrm{X}_{2} \\
\mathrm{SE}_{\text {diff }} & {\left[\left(\mathrm{SE}_{m}\right)^{2}+\left(\mathrm{SE}_{m}\right)^{2}\right]^{1 / 2}}
\end{array}
$$

Where:

$\mathrm{X}_{1}=$ participant's baseline score; $\mathrm{X}_{2}=$ participant's score at follow-up; $\mathrm{SE}_{\text {diff }}=$ Standard error of the difference; $\mathrm{SE}_{m}=$ Standard error of measurement

The percentage of patients who improved, were stable, or declined more than measurement error was calculated in each group (VNS, MC, RS). The proportion of cases in each category of change was subjected to Pearson Chi Square analysis.

Table 1: Demographics: age, education, WRAT-III Reading, interval between testing, distribution of sex and handedness in three epilepsy groups

\begin{tabular}{lccc}
\hline & $\begin{array}{c}\text { Vagus Nerve } \\
\text { Stimulator (VNS) } \\
\mathrm{n}=16\end{array}$ & $\begin{array}{c}\text { Medication } \\
\text { Controls (MC) } \\
\mathrm{n}=9\end{array}$ & $\begin{array}{c}\text { Cerebral Resective } \\
\text { Surgery (RS) } \\
\mathrm{n}=10\end{array}$ \\
\hline Mean Age in years $(s d)$ & $35(8.0)$ & $37(6.7)$ & $36(12.7)$ \\
Highest Grade $(s d)$ & $11(4.0)$ & $13(2.2)$ & $12(2.7)$ \\
$\begin{array}{l}\text { WRAT-III Reading } \\
\text { Score }(s d)\end{array}$ & $86(21.7)$ & $94(16.7)$ & $88(19.2)$ \\
$\begin{array}{l}{ }^{1} \text { Test-Retest Interval in } \\
\text { months }(s d)\end{array}$ & $13(3.0)$ & $13(1.1)$ & $19(6.7)$ \\
Male/Female Ratio & $9 / 7$ & & $4 / 6$ \\
${ }^{a}$ Handedness LA/R & $4 / 12$ & $2 / 7$ & $1 / 9$ \\
\hline
\end{tabular}

${ }^{1}$ One-way ANOVA F $=8.1$, df 2, $32 p<.001 ;{ }^{a}$ L or A, R Left- handed or ambidextrous, right handed

\section{RESULTS}

Patient demographics presented in Table 1 are based on all participants who were tested twice (i.e., all patients except for two MC patients who were lost to follow-up).
The only statistically significant group difference in Table 1 was length of interval from first to second testing. The RS cases were tested 12 months post-operatively. Because this group was first assessed six to seven months before surgery, their inter-test interval was longest.

Table 2 shows the mean frequency of complex partial seizures, the mean percentage change in seizure frequency (i.e., $17.7 \%$ ), and VNS stimulation parameters for the VNS group.

Table 2: VNS cases: seizure frequencies and stimulation

\begin{tabular}{|c|c|c|c|c|c|}
\hline $\begin{array}{r}\text { VNS Case } \\
\#\end{array}$ & $\begin{array}{l}\text { Time } 1 \\
\text { Total \# } \\
\text { CPS/m }\end{array}$ & $\begin{array}{l}\text { Time } 2 \\
\text { Total \# } \\
\text { CPS/m }\end{array}$ & $\begin{array}{r}\% \text { Change } \\
\text { in Sz } \\
\text { Frequency }\end{array}$ & $\begin{array}{r}\text { Magnet } \\
\text { Current } \\
(\mathrm{mA}) \text { Time } 2\end{array}$ & $\begin{array}{r}\text { Output } \\
\text { Current } \\
(\mathrm{mA}) \text { Time } 2\end{array}$ \\
\hline 1 & 10.0 & 8.6 & -14 & 2.0 & 1.75 \\
\hline 2 & 16.0 & 13.0 & -19 & 0.5 & 2.25 \\
\hline 3 & 19.0 & 24.0 & 26 & 2.0 & 3.0 \\
\hline 4 & 10.0 & 13.3 & 33 & 2.5 & 2.0 \\
\hline 5 & 30.0 & 3.0 & -90 & 1.25 & 1.75 \\
\hline 6 & 17.0 & 12.0 & -29 & 1.5 & 1.75 \\
\hline 7 & 350.0 & 336.0 & -4 & 2.0 & 2.0 \\
\hline 8 & 19.0 & 27.9 & 47 & 1.5 & 2.5 \\
\hline 9 & 24.0 & 19.3 & -20 & 1.5 & 1.5 \\
\hline 10 & 42.0 & 15.5 & -63 & 2.0 & 1.75 \\
\hline 11 & 41.5 & 40.5 & -2 & 2.5 & 2.5 \\
\hline 12 & 28.6 & 17.0 & -41 & 2.0 & 2.25 \\
\hline 13 & 38.0 & 22.0 & -42 & 2.25 & 2.0 \\
\hline 14 & 2.0 & 3.0 & 50 & 1.5 & 1.5 \\
\hline 15 & 4.5 & 5.0 & 11 & 1.25 & 1.75 \\
\hline 16 & $\underline{135.0}$ & $\underline{60.0}$ & $\underline{-55}$ & $\underline{1.25}$ & $\underline{1.25}$ \\
\hline Mean & 49.2 & 38.8 & -13.25 & 1.72 & 2.0 \\
\hline$s d$ & 85.9 & 80.6 & 40.1 & 0.53 & 0.47 \\
\hline
\end{tabular}
parameters

Note. $\mathrm{CPS} / \mathrm{m}=$ Complex Partial seizures per month; $>-50 \%$ change in seizure frequency represents a responder

In this sample, $3 / 16(18.8 \%)$ of VNS cases were responders, i.e., they obtained $50 \%$ or greater reduction in seizure frequency, whereas 11/16 (69\%) had some reduction in seizure frequency (see Table 2).

\section{Group Analyses \\ Self-report scores}

Figures 1,2, and 3 illustrate Time 1 and Time 2 ratings for quality of life, depressive symptoms, and memory complaints broken down by group. Note that not all participants' data were available for every analysis, resulting in variability in the sample sizes presented in Figures 1, 2 and 3. Significant main effects of time were found for the QOLIE-89 Total Score (Figure 1), F = 10.0 , df $1,19, p<.005$; the GDS, $\mathrm{F}=4.2$, df $1,20, p<.05$; and the MOQ-SA, $\mathrm{F}=4.3$, df $1,24, p<.05$ indicating that all participants improved on the second testing compared to the 


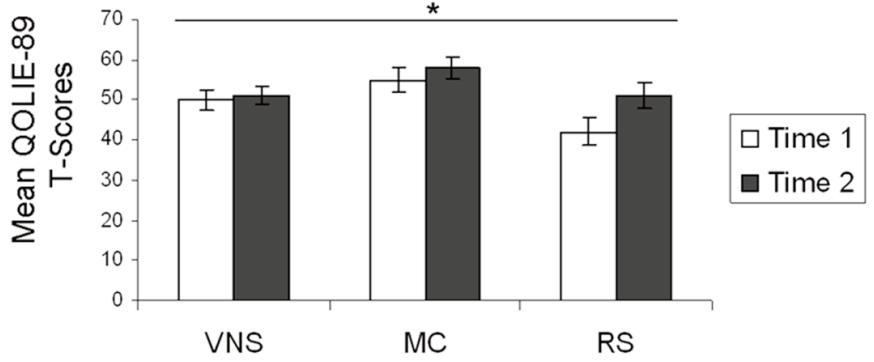

Figure 1: Patient Report of Quality of Life Improves Despite Differences in Intervention. Note: QOLIE-89=Quality of Life in Epilepsy - 89; VNS=Vagus Nerve Stimulus group $(N=10)$; $M C=$ Medical Control group $(n=7) ; R S=$ Resective Surgery group $(n=5)$; *Signifies a main effect of time.

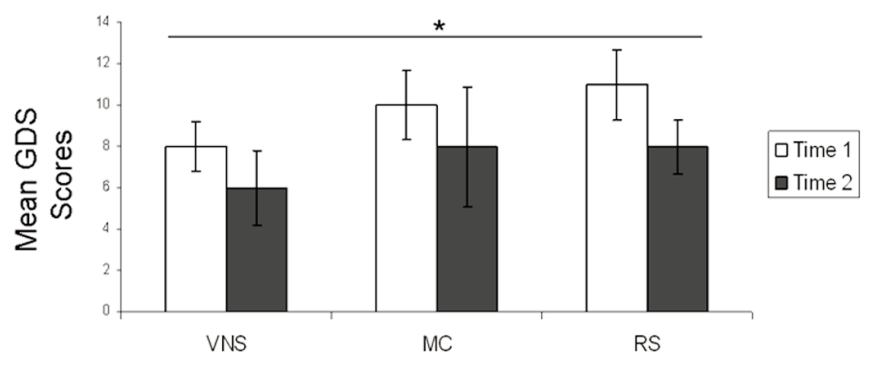

Figure 2: Patient Report of Depressive Symptoms Improves Over Time Regardless of Differences in Intervention. Note: GDS=Geriatric Depression Scale; VNS=Vagus Nerve Stimulus group $(n=12) ;$ MC=Medical Control group $(n=6) ; R S=$ Resective Surgery group $(n=6) ; *$ Signifies a main effect of time.

first. A main effect for time was not found on the MOQ-SB, MOQ-RA, or the MOQ-RB. There were no significant Group effects or Group by Time interactions, indicating that the groups did not differ over the course of time with respect to their improvement on the measures. Hence there was no trend for VNS cases to rate their QOL to be better than medication controls or patients undergoing RS.

\section{Memory Battery}

Figure 4 contains the eight WMS-III Indices for all three groups at baseline and follow-up, broken down by memory, verbal, and auditory indices.

A significant main effect of Group occurred on three of the eight memory Indices from the WMS-III (i.e., Immediate Memory F $=3.4$, df 2,30, $p<.05$; Immediate Visual Memory F $=4.6$, $\mathrm{df} 2,30, p<.02$; and Delayed Visual Memory $\mathrm{F}=3.7$, $\mathrm{df}$ $2,30, \mathrm{p}<.04)$. Post hoc Bonferroni t-tests showed that the MC group obtained higher scores than the RS group post-operatively on all three measures $(p<.05)$. Similarly, MC were significantly higher than VNS on the Visual Immediate Index of the WMS-III $(p<.05)$. There was no effect of Time on any memory index.

Although a main effect of Time was not found on any memory indices, two of the memory indices showed a significant

\section{A. Patient Self-Report of Memory Function}

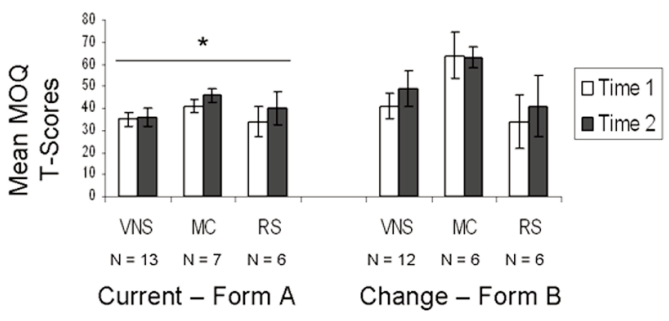

B. Relative Report of Memory Function

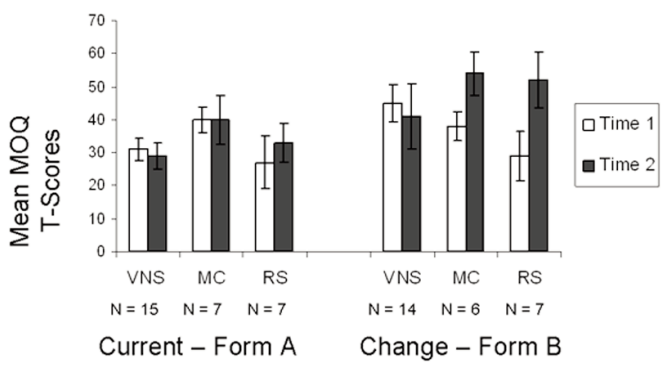

Figure 3: Patient and Relative Report of Memory Improves or Remains Stable Despite Differences in Intervention. Note: MOQ=Memory Observation Questionnaire; VNS=Vagus Nerve Stimulus group; $M C=$ Medical Control group; RS=Resective Surgery group; *Signifies a main effect of time on this form.

interaction of Group by Time (i.e., Immediate Memory F $=3.3$, df $2,30, p<.05$; and Working Memory $\mathrm{F}=3.5$, df 2,30, $<.04$ ). Post hoc Bonferroni t-tests revealed no significant differences in the scores; however, there was a trend for improved Working Memory post-surgically in the RS group only. By contrast, RS reduced their Immediate Memory scores post-surgically, while the two other groups showed small increases (changes not significant). Other neuropsychological measures administered during the evaluation (i.e., Stroop Colour Word Test, Trail Making A and B, Finger Tapping, Oral Fluency words beginning with "d", Oral Fluency animals, Boston Naming Test; see Appendix A for a description of these tests) showed no differences except that $\mathrm{MC}$ showed the fastest right hand tapping speed (mean taps in 10 seconds $\mathrm{MC}=50, \mathrm{RS}=45$, $\mathrm{VNS}=42$; Group $\mathrm{F}=4.0$, df 2, 26, $p<.03$ ).

Summarizing the ANOVA analyses, QOL, depression, and memory outcomes for VNS, RS, and MC participants were not significantly different. All seizure groups rated themselves as having a better quality of life, less dysphoria, and fewer memory complaints (on the MOQ-SA, but not the MOQ-SB, MOQ-RA, or the MOQ-RB) on the second evaluation 12 months after the first, regardless of intervention status. Objective memory scores did not change significantly. The small sample size in this study means there is not enough power to detect significant group interactions if they were present (although main effects could be identified), so we next compared the incidence of real change for each case by calculating the RCI. 

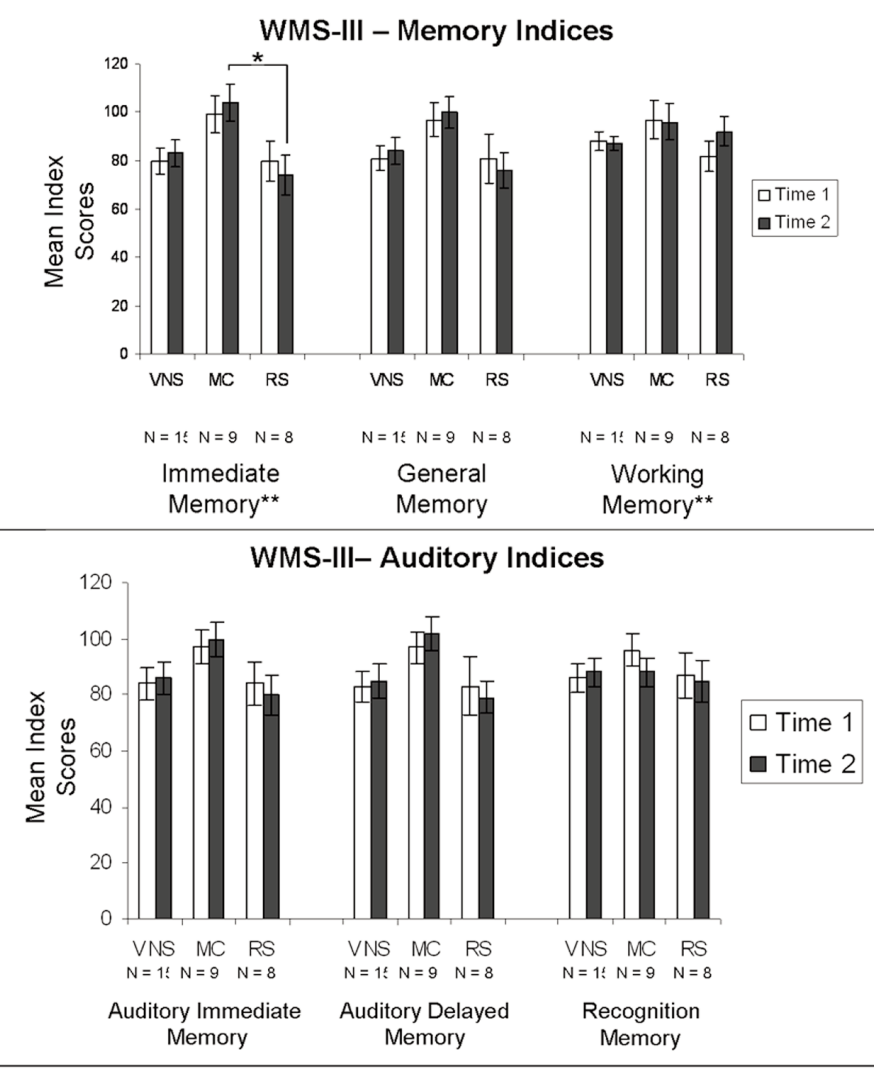

WMS-III - Visual Indices

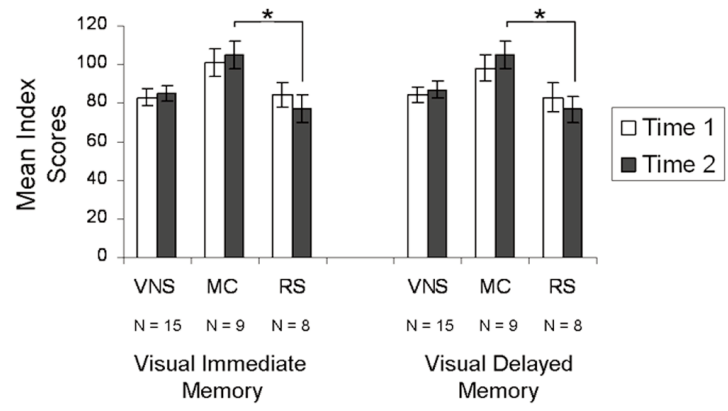

Figure 4: There are few differences among VNS, MC, and RS Groups on WMS-III Indices. Note: WMS-III=Weschler Memory Scale; VNS=Vagus Nerve group; $M C=$ Medical Control group; $R S=$ Resective Surgery group; *Signifies a main effect of group and post hoc tests reveal significant difference between $M C$ and $R S$ post-operative scores; **Signifies a significant interaction on these indices. Please see Results section for a description of these interactions.

\section{Reliable Change Index}

\section{Self-report scores}

The quality of life outcome measure graphed in Figure 5 showed that proportionately more RS cases improved than the VNS cases in aggregate QOLIE-89 ratings (Chi Square 7.4, $2 \mathrm{df}$, $p<.03)$. There was no significant difference among groups on the depression inventory (Figure 6) or MOQ scores (Figure 7).

We also examined whether achieving $>50 \%$ reduction in

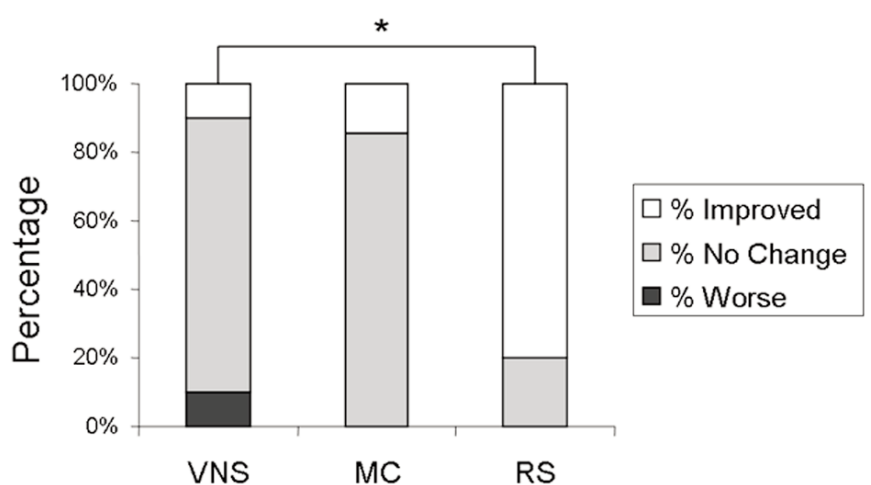

Figure 5: Resective surgery group improved more than vagus nerve stimulation group on quality of life based on reliable change index. Note: GDS=Geriatric Depression Scale; VNS=Vagus Nerve Stimulus group; $M C=$ Medical Control group; RS=Resective Surgery group; *Signifies a significant difference between the VNS and RS groups using Chi Squared analyses.

seizure frequency in the VNS group resulted in better ratings of QOL using the RCI followed by a Pearson Chi square analysis comparing differences. A decrease in seizure frequency in three patients in the VNS group was not associated with an improvement in their QOL ratings (Chi square $=0.3,1 \mathrm{df}$, ns). Memory scores

The overall incidence of change on objective memory scores was not significantly different in all three groups; however, on the Auditory Recognition Index (1 of the 8 indices), significantly more cases with VNS improved their Auditory Recognition Index than did MC (Chi square $=7.0,2 \mathrm{df}, p<.03$ ). Multiple Pearson Chi Square analyses showed that more RS cases declined than VNS cases on three WMS-III memory indices (i.e., General Memory Chi square $=6.2 ; 2 \mathrm{df}, p<.05$; Auditory Immediate Chi square 6.5, $2 \mathrm{df}, p<.04$, and Auditory Delayed Chi square $=7.52 \mathrm{df}, p<.02$ ).

\section{DISCUSSION}

Patients with VNS, MC and RS all rated their quality of life, depressive affect, and memory complaints as improved on the second occasion, even though medically managed cases had no additional surgical intervention to help control their seizures. Hence the current case control design was not able to show that QOL improved for VNS managed cases more than other medically managed epilepsy patients. That medically managed cases with temporal lobe epilepsy report significantly improved QOL after one year has already been documented within a randomized control study. ${ }^{32} \mathrm{We}$ also think that sham stimulation designs (i.e., stimulation below therapeutic threshold) may not be a sufficient control condition, since even low level stimulation is physiologically perceived, and QOL self-ratings are influenced by an active placebo. For example, similar QOL increases were reported by the low and the high stimulation VNS epilepsy groups in Dodrill and Morris. ${ }^{20}$ The fact that self-ratings of quality of life improved to the same degree under active placebo condition compared to clinically effective VNS 


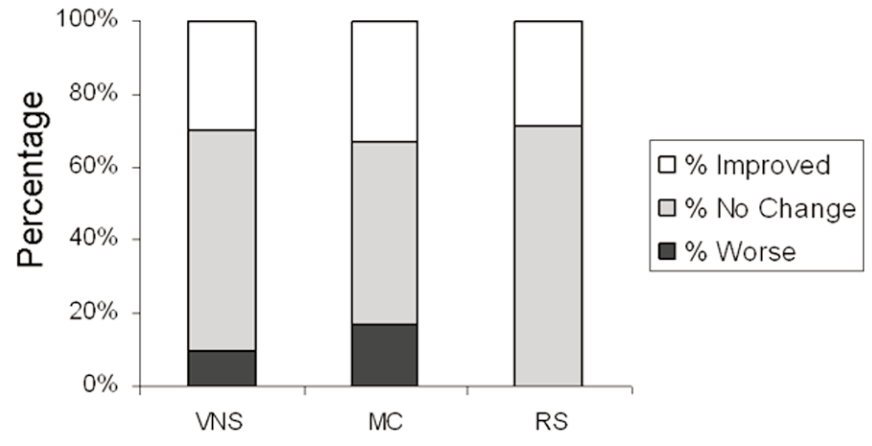

Figure 6: No Significant Difference Among Groups For Change in Depression (Geriatric Depression Scale Scores) Based on Reliable Change Index. Note: VNS=Vagus Nerve Stimulation group; $M C=$ Medical Control group; $R S=$ Resective Surgery group.

conditions means that future experimental designs need to include control groups other than patients given perceptible physiological sensations associated with low VNS parameters to address the issue that expectancies play an important role in clinical outcomes studies. ${ }^{42-44}$

In our sample, VNS cases who experienced $>50 \%$ reduction in seizure frequency were less likely to rate their quality of life as improved compared to VNS cases with $<50 \%$ seizure reduction, a finding that is consistent with aggregate score QOL measures on several large scale studies. ${ }^{45}$ Despite earlier claims to the contrary, ${ }^{46}$ we suggest that the literature has yet to prove with rigorous scientific methods that seizure patients implanted with a VNS experience concomitant changes in their quality of life more so than control groups.

On the other hand, and consistent with the literature on temporal lobe resective surgery, ${ }^{21}$ our small sample of RS patients rated their quality of life as significantly improved and significantly more so compared to the VNS group. Improvement in quality of life after cerebral resective surgery for epilepsy has been correlated with being seizure free, ${ }^{34,47}$ having a markedly reduced seizure frequency, ${ }^{48,49}$ or having fewer than one seizure per month. ${ }^{50}$

Although we chose to analyze the aggregate QOLIE-89 score, it can be argued that total scores can hide real improvements only seen in certain aspects of life satisfaction. For example, von Steinbüchel et $\mathrm{al}^{51}$ recommended that aggregate QOL measures be used for cost-utility studies, but that profile domains of QOL be used to detect treatment effects. To test this possibility, we conducted additional RCI analyses, and Pearson Chi square analyses on the 17 subscales from the QOLIE-89 (T-scores). The proportion of cases in each group did not differ in percent improved or declined on any of the 17 subscales.

This 12 month follow-up study found no changes in objective memory scores after VNS, with one possible exception using an $\mathrm{RCI}$ approach. The one exception was that Chi square analyses of Auditory Recognition Memory showed that proportionately more VNS cases improved than Medication Controls or RS cases although no mean differences were found on the ANOVA. It is

\section{A. Patient Self-Report of Memory Function}

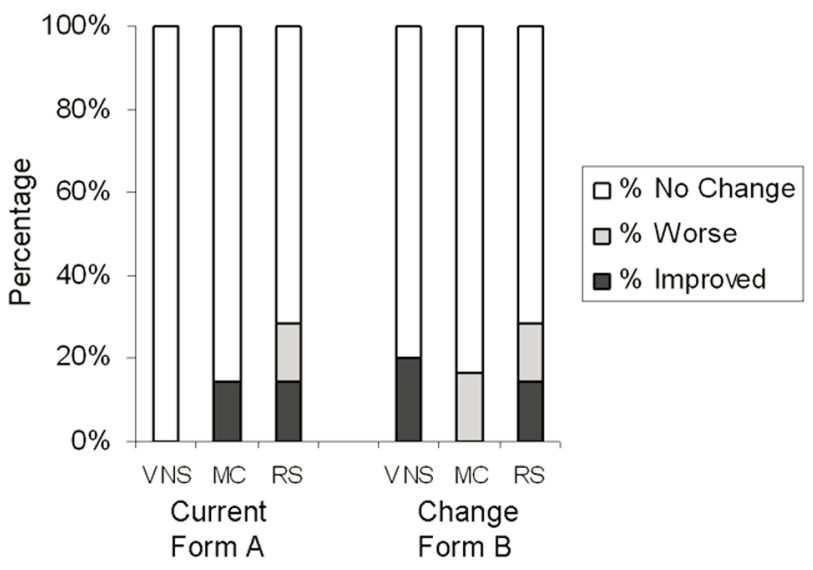

\section{B. Relative-Report of Memory Function}

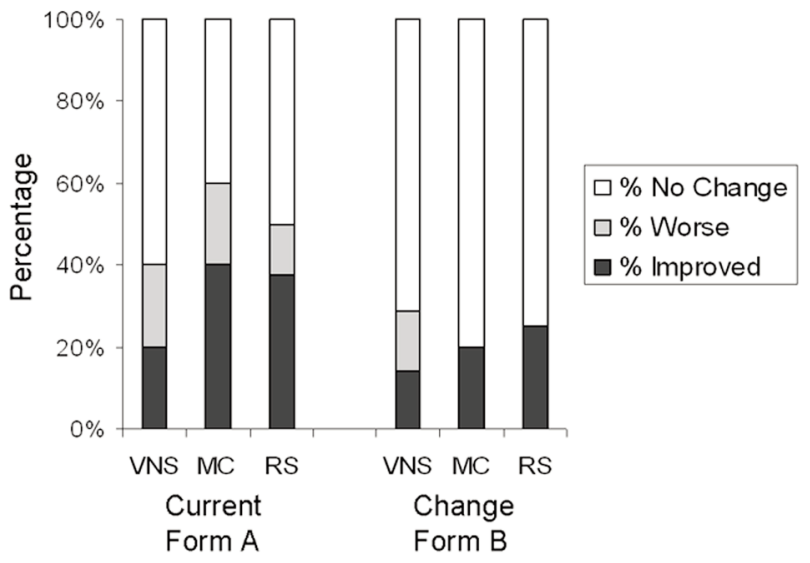

Figure 7: No Significant Differences Among the Groups for Subjective Memory Based on Reliable Change Index as self-reported by Patient $(A)$ or Relative (B). Note: $M O Q=$ Memory Observation Questionnaire; VNS=Vagus Nerve Stimulation group; $M C=$ Medical Control group; $R S=$ Resective Surgery group.

possible that the non-significant ANOVA relates to lack of power, although the equivalent means do not support this interpretation. Our finding is unique in the literature, and it is not based on prior theoretical hypotheses or empirically derived findings. Until replicated, improvement in Auditory Recognition Memory after VNS might best be viewed as a Type II error secondary to the large number of exploratory analyses conducted. This study supports conclusions that therapeutic VNS does not interfere with the day-to-day cognitive abilities of patients and, importantly also indicates that VNS does not interfere with most memory functions. Claims that VNS stimulation, "show reversal of the pattern of baseline deficits ..." might best be interpreted as practice effects rather than VNS treatment effects. ${ }^{29}$ 
Finally, it should be noted that industry has funded the vast majority of VNS investigations and investigators who have examined psychosocial outcomes of implantation of a VNS. Whether industry-sponsored research programs alone are in the best position to provide the scientific community with independent criticism of the procedures is under active scrutiny. ${ }^{52}$ The manufacturers, treating clinicians, and the patient with refractory seizures each carry vested interests and positive expectations that a new treatment option will improve outcomes. It is telling that in the only large scale non-industry funded VNS outcome study published to date, ${ }^{53}$ patients paid for the device, and reported two-thirds reduction in frequency of complex partial seizures (from 21 to 7 per month). We suggest that hopefulness, optimism, placebo effects, investigator allegiance and bias influences outcomes and need to be controlled in future VNS studies..$^{54}$

\section{Limitations of this Study}

The sample size is underpowered to find small to moderatelysized group differences in ANOVAs (although large effects may be detected), but this limitation is not applicable to the RCI analyses. Another limitation of our non-randomized study is that patients selected for VNS were heterogeneous, the most difficult to manage, half had failed prior surgical as well as medical treatments, and changes in medications were not controlled. Detecting change in the most refractory cases often proves elusive. Although our study did not uncover major advantages of VNS over medical management in psychosocial or memory outcomes (except perhaps for verbal recognition memory scores), others have shown that direct epilepsy-related costs are reduced in VNS compared with medically treated patients. ${ }^{53}$ There may be indirect benefits as well - for example, VNS provided life-enhancing and dramatic reduction in migraine attacks for one person. ${ }^{53}$ Moreover, our patients and clinicians agreed that some potential benefits of VNS were not captured by the current measures, since we did not examine changes in seizure severity or pattern.

Finally, the QOLIE-89 is a disease specific questionnaire normed on persons with epilepsy. The QOLIE-89 was designed to tap adverse effects of new seizure medications, not the somewhat different set of side effects associated with VNS implantation and stimulation such as hoarseness, coughing, throat pain, dyspnea. ${ }^{55}$ Omitting known side effects of VNS from all QOL measures necessarily biases outcomes in a positive direction, and future researchers may wish to add VNS specific items to the QOLIE-89. Despite its limitations, we hope that the current study design can inform the scientific community, and create a demand for more rigorous evidence in future programs demonstrating efficacy and effectiveness for this relatively new treatment of persons with epilepsy.

\section{ACKNOWLEDGEMENTS}

The authors thank Susan Rahey and Anita Scott for record keeping and data analyses, respectively. Shirley Munk provided some of the neuropsychological evaluations. This study was funded locally by the Queen Elizabeth II Research Fund and by the Epilepsy Association of Nova Scotia.

\section{Disclosure of Conflicts of INTEREST}

Dr. Sadler received research funding from Cyberonics for participation in a trial of vagus nerve stimulation beginning in 2006.

\section{REFERENCES}

1. George M, Sackeim H, Rush A, Marangell L, Nahas Z, Husain M, et al. Vagus nerve stimulation: a new tool for brain research and therapy. Biol Psychiatry. 2000; 47: 287-95.

2. Ben-Menachem E, Manon-Espaillat R, Ristanovic R, Wilder B, Stefan H, Mirza W, et al. Vagus nerve stimulation for treatment of partial seizures: 1. a controlled study of effect on seizures. Epilepsia. 1994; 35: 616-26.

3. Handforth A, DeGiorgio C, Schachter S, Uthman B, Naritoku D, Tecoma E, et al. Vagus nerve stimulation therapy for partialonset seizures. A randomized active-control trial. Neurology. 1998; 51: 48-55.

4. Vonck K, Boon P, D'Have M, Vandekerckhove T, O'Connor S, De Reuck J. Long-term results of vagus nerve stimulation in refractory epilepsy. Seizure. 1999; 8: 328-34.

5. Morris G, Mueller W. The Vagus Nerve Stimulation Group. Longterm treatment with vagus nerve stimulation in patients with refractory epilepsy. Neurology. 1999; 53: 1731-5.

6. Amar AP, Apuzzo ML, Liu CY. Vagus nerve stimulation therapy after failed cranial surgery for intractable epilepsy: results from the vagus nerve stimulation therapy patient outcome registry. Neurosurgery. 2004; 55: 1086-93.

7. Renfroe JB, Wheless JW. Earlier use of adjunctive vagus nerve stimulation therapy for refractory epilepsy. Neurology. 2002; 24 Suppl 4: S26-30.

8. The Vagus Nerve Stimulation Study Group. A randomized controlled trial of chronic vagus nerve stimulation for treatment of medically intractable seizures. Neurology. 1995; 45: 224-30.

9. Chadwick D. Vagal-nerve stimulation for epilepsy. Lancet. 2001; 357: 1726-7.

10. Baker GA, Gagnon D, McNulty P. The relationship between seizure frequency, seizure type and quality of life: findings from three European countries. Epilepsy Res. 1998; 30: 231-40.

11. Devinsky O. Quality of life in epilepsy. Time to practice what we preach. Epilepsy Behav. 2000; 1: 89-90.

12. Sirven J, Sperling M, Naritoku D, Schachter S, Labar D, Holmes M, et al. Vagus nerve stimulation therapy for epilepsy in older adults. Neurology. 2000; 54: 1179-82.

13. Cramer J. Exploration of changes in health-related quality of life after three months of vagus nerve stimulation. Epilepsy Behav. 2001; 2: 460-5.

14. Ergene E, Behr P, Shih J. Quality-of-life assessment in patients treated with vagus nerve stimulation. Epilepsy Behav. 2001; 2: 284-7.

15. McLachlan R, Sadler M, Pillay N, Guberman A, Jones M, Wiebe S, et al. Quality of life after vagus nerve stimulation for intractable epilepsy: Is seizure control the only contributing factor? Eur Neurol. 2003; 50: 16-19.

16. Morrow JI, Bingham E, Craig JJ, Grey, WJ. Vagus nerve stimulation in patients with refractory epilepsy. Effect on seizure frequency, severity and quality of life. Seizure. 2000; 9: 442-5.

17. Chavel SM, Westerveld M, Spencer S. Long-term outcome of vagus nerve stimulation for refractory partial epilepsy. Epilepsy Behav. 2003; 4: 302-9

18. Gill T, Feinstein A. A critical appraisal of the quality of quality-oflife measurements. JAMA. 1994; 272: 619-26.

19. Hoppe C, Helmstaedter C, Scherrmann J, Elger CE. Self-reported mood changes following 6 months of vagus nerve stimulation in epilepsy patient. Epilepsy Behav. 2001a; 4: 335-42.

20. Dodrill C, Morris G. Effects of vagal nerve stimulation on cognition and quality of life in epilepsy. Epilepsy Behav. 2001; 2: 46-53.

21. Baker G, Jacoby A. Quality of life in epilepsy. Amsterdam: Harwood Academic Publishers; 2000.

22. Wiebe S, Matijevic S, Eliasziw M, Derry P. Clinically important 
change in quality of life in epilepsy. J Neurol Neurosurg Psychiatry. 2002; 73: 116-20.

23. Fisher R, Handforth A. Reassessment: Vagus nerve stimulation for epilepsy: A report of the Therapeutics and Technology Assessment Subcommittee of the American Academy of Neurology. Neurology. 1999; 53: 666-9.

24. Clark K, Naritoku D, Smith D, Browning R, Jensen R. Enhanced recognition memory following vagus nerve stimulation in human subjects. Nat Neurosci. 1999; 2: 94-8.

25. Ghacibeh GA, Shenker JI, Shenal B, Uthman BM, Heilman KM. The influence of vagus nerve stimulation on memory. Cog Behav Neurol. 2006; 19: 199-22.

26. Helmstaedter C, Hoppe C, Elger C. Memory alterations during acute high-intensity vagus nerve stimulation. Epilepsy Res. 2001; 47: 37-42.

27. Hoppe C, Helmstaedter C, Scherrmann J, Elger CE. No evidence for cognitive side effects after six months of vagus nerve stimulation in epilepsy patients. Epilepsy Behav. 2001b; 2: 351-6.

28. Clarke B, Upton A, Griffin H. Cognitive motor function after electrical stimulation of the vagus nerve. Pacing Clin Electrophysiol. 1992; 15: 1603-7.

29. Sackeim H, Keilp J, Rush A, George M, Marangell L, Dormer J, et al. The effects of vagus nerve stimulation on cognitive performance in patients with treatment-resistant depression. Neuropsychiatry Neuropsychol Behav Neurol. 2001; 14: 53-62.

30. Small S. Age related memory decline. Arch Neurol. 2001; 58: 360-4.

31. Jacobson N, Truax P. Clinical significance: A statistical approach to defining meaningful change in psychotherapy research. J Consult Clin Psychol. 1991; 59: 12-19.

32. Wiebe S, Blume W, Girvin J, Eliasziw M. A randomized, controlled trial of surgery for temporal-lobe epilepsy. N Eng J Med. 2001; 345: $311-8$.

33. Wilkinson G. WRAT 3 Administration Manual. Wide Range, Wilmington; 1993.

34. Devinsky O, Vickrey BG, Cramer J, Perrine K, Hermann B, Meador $\mathrm{K}$, et al. Development of the Quality of Life in Epilepsy Inventory. Epilepsia. 1995; 36: 1089-104.

35. Harden C, Pulver M, Ravdin L, Nikolov B, Halper J, Labar D. A pilot study of mood in epilepsy patients treated with vagus nerve stimulation. Epilepsy Behav. 2000; 1: 93-9.

36. Yesavage J, Brink T, Rose T, Adey M. The geriatric depression scale: Comparison with other self-report and psychiatric scales. In: Crook J, Ferris S, Bartus R, editors. Assessment in geriatric psychopharmacology. Mark Prowley Associates, Connecticut; 1986. p. 153-67.

37. Montorio I, Izal M. The Geriatric Depression Scale: A review of its development and utility. Int Psychogeriatr. 1996; 8: 103-12.

38. Humphrey D, McGlone J, Leffley A, Gupta S, Evans D. Manual for the Memory Observation Questionnaire and Memory Observation Questionnaire - 2. King's College, London, Ontario; 1992.

39. Wechsler D. WMS-III Administration and Scoring Manual. The Psychological Corporation, San Antonio; 1997.

40. McGlone J, Wands K. Self-report of memory function in patients with temporal lobe epilepsy and temporal lobectomy. Cortex. 1991; 27: 19-28.

41. McGlone J. Memory complaints before and after temporal lobectomy: Do they predict memory performance or lesion laterality? Epilepsia. 1994; 35: 529-39.

42. Fisher S, Greenberg RP. The limits of biological treatments for psychological distress: Comparisons with psychotherapy and placebo. Lawrence Erlbaum Associates, New Jersey; 1989.

43. Kirsch I. Conditioning, expectancy, and the placebo effect: A comment on Stewart-Williams and Podd. Psychol Bull. 2004; 130: 341-3.

44. Kirsch I, Sapirstein G. Listening to Prozac but hearing placebo: A meta-analysis of antidepressant medication. Prevention \& Treatment. 1998; 1, published online: http://journals.apa.org/ prevention/volume1/pre0010002a.html.
45. Ergene E, Behr PK, Shih JJ. Quality-of-life assessment in patients treated with vagus nerve stimulation. Epilepsy Behav. 2001; 2: 284-7.

46. Labar D. Effects of vagal nerve stimulation on cognition and quality of life. Epilepsy Behav. 2001; 2: 161-2.

47. Baker G, Camfield C, Camfield P, Cramer J, Elger C, Johnson A, et al. ILAE Commission Report Commission on outcome measurement in Epilepsy, 1994-1997: Final Report. Epilepsia. 1998; 39: 213-31.

48. Kellett M, Smith D, Baker G, Chadwick D. Quality of life after epilepsy. J Neurol Neurosurg Psychiatry. 1997; 63: 52-8.

49. Leidy N, Elixhauser A, Vickrey B, Means E, Willian M. Seizure frequency and the health-related quality of life of adults with epilepsy. Neurology. 1999; 53: 162-6.

50. Baker G, Jacoby A, Buck D, Stalgis C, Monnet D. Quality of life of people with epilepsy: a European study. Epilepsia. 1997; 38 : 353-62.

51. von Steinbuchel N, Heel S, Bullinger M. Review of health-related measures of quality of life pertaining to epilepsy which are currently. In Baker G, Jacoby A, editors. sQuality of Life in epilepsy: beyond seizure counts in assessment and treatment. London: Harwood Press; 2000. p. 65-102.

52. Wilkins D. Reassessment: vagus nerve stimulation for Epilepsy. Neurology. 2000; 54: 2027.

53. Boon P, D'Have M, Van Walleghem P, Michielsen G, Vonck K, Caemaert J, et al. Direct medical costs of refractory epilepsy incurred by three different treatment modalities: a prospective assessment. Epilepsia. 2002; 43: 96-102.

54. Harden CL, Pulver MC, Ravdin LD, Nikolov, B, Halper JP, Labar DR. A pilot study of mood in epilepsy patients treated with vagus nerve stimulation. Epilepsy Behav. 2000; 1: 93-9.

55. Krapohl BD, Deutlinger M, Kömürcü F. Vagus nerve stimulation: treatment modality for epilepsy. Medsurg Nurs. 2007; 16: $39-44$.

\section{APPENDIX A}

Neuropsychological Tests Administered (In addition to the WMS-III):

Test Name

Boston Naming Test*1

\section{Description}

60-item test which assesses a patient's ability to name objects of varying frequencies from line drawings. It is generally used to detect nominal aphasia and higher scores indicate better naming ability.

\section{The Stroop Color and Word Test ${ }^{2} 2$}

Measures cognitive flexibility and resistance to interference from outside stimuli. Patients are asked to look at three pages, one at a time, and either read words, or say the names of the ink colours that the words are printed in as quickly as possible. First, the words "RED", "GREEN", and "BLUE" are printed in black ink and the patient must read the words. Next, a meaningless symbol is printed in various colours and the patient is required to say aloud the ink colours. Finally, the words from the first page are printed in various ink colours and the patient is required to say aloud the ink colors. 
Verbal Fluency

The Trail Making Test $A$ and $B^{* 4}$

Tests of verbal fluency assess executive functions and language ability*3. In this study, oral fluency was assessed by asking the patient to name all the words possible in a minute beginning with the letter 'd'. Semantic fluency was assessed by asking the patient to name all the animals possible in a minute.

Assesses visual conceptual and visuomotor tracking, involving motor speed and attention functions. In part A, patients are asked to connect encircled numbers randomly spread on a sheet of paper (numbers $1-25$ ) in as little time as possible. Part B requires patients to connect numbers and letters in an alternating pattern (1-A-2-B-3-C, ect.) in as little time as possible.

Finger Tapping Test ${ }^{* 5} \quad$ A simple measure of motor speed and motor control during which the patient is required to tap his or her right and left index fingers as quickly as possible for 10 seconds. The mean of two trials is taken.

\section{REFERENCES (For APPENDIX A)}

1. Kaplan E, Goodglass H, Weintraub, S. Boston Naming Test. Philadelphia: Lea \& Febiger; 1983.

2. Golden C (1978) Stroop color and word test manual, Chicago: Stoelting Co; 1978.

3. Brickman AM, Paul RH, Cohen RA, Williams LM, MacGregor KL, Jefferson AL, et al. Category and letter verbal fluency across the adult lifespan: Relationship to EEG theta power. Arch Clin Neuropsychol. 2005; 20:561-573.

4. Reitan RM. Trail Making Test: Manual for administration and scoring. South Tucson, AZ: Reitan Neuropsychology Laboratory; 1992.

5. Reitan RM, Davison LA. Clinical neuropsychology: Current status and applications. New York: Hemisphere; 1974. 